\title{
Technical Note: On the effect of water-soluble compounds removal on EC quantification by TOT analysis in urban aerosol samples
}

\author{
A. Piazzalunga ${ }^{1, *}$, V. Bernardoni ${ }^{2}$, P. Fermo ${ }^{1}$, G. Valli ${ }^{2}$, and R. Vecchi ${ }^{2}$ \\ ${ }^{1}$ Department of Inorganic, Metallorganic and Analytical Chemistry, Università degli Studi di Milano, Via Venezian 22, \\ 20133 Milan, Italy \\ ${ }^{2}$ Department of Physics, Università degli Studi di Milano, Via Celoria 16, \\ 20133 Milan, Italy \\ * now at: Department of Environmental and Territorial Sciences, Università di Milano-Bicocca, Piazza della Scienza 1, \\ 20126 Milan, Italy
}

Received: 16 May 2011 - Published in Atmos. Chem. Phys. Discuss.: 12 July 2011

Revised: 13 September 2011 - Accepted: 20 September 2011 - Published: 11 October 2011

\begin{abstract}
In this work, three different thermal protocols were tested on untreated and water-washed aerosol samples to study the influence of soluble organic and inorganic compounds on EC measurements. Moreover, analyses on the water soluble extracts were carried out. The aim was to find out the most suitable protocol to analyse samples collected in a heavily polluted area. Indeed, the tests were performed on real samples collected at an urban background station in the Po Valley, which is one of the main pollution hot-spots in Europe.

The main differences among the tested protocols were the maximum temperature of the $\mathrm{He}$ step (i.e. $870^{\circ} \mathrm{C}, 650^{\circ} \mathrm{C}$, and $580^{\circ} \mathrm{C}$ ) and the duration of the plateaus during the heating procedure. Our measurements evidenced the presence of a significant amount of weakly light-absorbing carbonaceous aerosol evolving during the highest temperature step in $\mathrm{He}$ (i.e. $870^{\circ} \mathrm{C}$ ), which makes lower temperature protocols not suitable for EC determination in samples collected in heavily polluted areas like Milan.
\end{abstract}

\section{Introduction}

At the state of the art the identification of organic (OC) and elemental (EC) carbon in aerosol samples using thermal protocols is ambiguous; therefore, they are operationally defined. Indeed, part of the EC thermally evolves in oxidis-

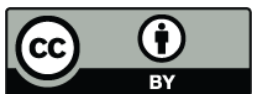

Correspondence to: A. Piazzalunga (andrea.piazzalunga@unimib.it) ing atmosphere and part of the OC can char especially in an oxygen-poor atmosphere giving origin to a refractory component (pyrolytic carbon, PyC) similar to EC (Watson et al., 2005; and therein cited literature).

Among the different approaches used for OC/EC quantitative evaluation, thermal-optical analyses are the most widespread (Chow et al., 1993; Birch and Cary, 1996). Different heating ramps both in $\mathrm{He}$ and $\mathrm{He} / \mathrm{O}_{2}$ phase are reported in the literature for thermal-optical analyses. It is noteworthy that temperature and duration of the plateaus have been already identified as the main factors influencing OC/EC separation (Chow et al., 2001, 2004; Schmid et al., 2001; Conny et al., 2003; Schauer et al., 2003; Subramanian et al., 2006; Zhi et al., 2009); a twofold difference in the EC quantification by different thermal-optical approaches is quite usual (e.g. Schmid et al., 2001; Watson et al., 2005; and therein literature).

$\mathrm{PyC}$ is considered one of the main interfering components in the EC quantification. Previous works (Chow et al., 2001; Subramanian et al., 2006) evidenced that EC and/or PyC pre-combustion can occur in the He phase at high temperature (i.e. about $850^{\circ} \mathrm{C}$ ) especially when inorganic catalytic compounds are present in the sample (Novakov and Corrigan, 1995; Chow et al., 2001; Yu et al., 2002; Wang et al., 2010). Moreover, the same authors singled out the presence of heavy, tar-like organic compounds which do not evolve until the highest temperature in $\mathrm{He}$ atmosphere is reached.

The water-soluble organic compounds (WSOC) removal has been identified as an effective procedure for a better EC quantification as WSOC have an important role in PyC formation (Novakov and Corrigan, 1995; Yu et al., 2002);

Published by Copernicus Publications on behalf of the European Geosciences Union. 
nevertheless - as far as we know - a systematic analysis of the results obtained by the thermal-optical analyses on real samples after WSOC removal has never been carried out. Moreover, some inorganic catalytic compounds as well as some polymeric, partially aromatic, coloured organic products of combustion which evolve only at high temperature are water soluble; thus, they can be removed by washing the filter before analysis in order to reduce possible catalytic effects or interferences in the EC determination (Andreae and Gelencsér, 2006).

The influence of the sample composition on the thermal behaviour of carbonaceous species makes difficult finding out a universal thermal method for OC/EC separation suitable for aerosol samples collected in different environments.

In this work, tests were carried out with the aim of identifying the most suitable protocol for OC/EC measurements on samples collected at an urban area in the Po Valley, which is one of the major pollution hot-spots in Europe. Three protocols mainly differing for the highest temperature in the inert atmosphere (i.e. $870^{\circ} \mathrm{C}, 650^{\circ} \mathrm{C}$, and $580^{\circ} \mathrm{C}$ ) were tested. The novelty of this work is that the tests were performed both on untreated and water-washed samples. In addition, WSOC extracted from our samples were also analysed to study their thermal behaviour and gain further information on the different carbonaceous aerosol components.

\section{Experimental methods}

\subsection{Samplings}

The sampling campaigns were carried out at an urban background station in the Milan university campus at about $10 \mathrm{~m}$ above ground level. $\mathrm{PM}_{10}$ was sampled on two parallel quartz fibre filters (2500 QAO-UP, Pall Corporation, $47 \mathrm{~mm}$ diameter) pre-fired at $700^{\circ} \mathrm{C}$ for $1 \mathrm{~h}$ (Vecchi et al., 2009) using low volume samplers (flow rate: $2.3 \mathrm{~m}^{3} \mathrm{~h}^{-1}$ ).

26 parallel samplings were carried out from 17 January to 9 February 2010. The sampling strategy was to perform $9 \mathrm{~h}$ samplings (from 09:00 to 18:00 and from 21:00 to 06:00 LT) in order to limit the filter loading and to operate the carbon analyses in optimal conditions (see Sect. 3.2).

During the sampling period the weather was cloudy or foggy (snow was registered on 5 February 2010 and no other precipitations occurred in the period). Temperature ranged from $-1{ }^{\circ} \mathrm{C}$ to $10^{\circ} \mathrm{C}$. $\mathrm{PM}_{10}$ mass was $74 \mu \mathrm{g} \mathrm{m}^{-3}$ on average (range 35-111 $\mu^{-3} \mathrm{~m}^{-3}$ ), and total carbon (TC) accounted for about $25 \%$ of the $\mathrm{PM}_{10}$ mass on average.

\subsection{Thermal-optical transmittance analysis}

In this work, a thermal-optical transmittance (TOT) analyser by the Sunset Laboratory Inc. was used to quantify EC, OC, and TC in aerosol samples. The carbonatic carbon component was not considered in this work as previous studies reported that carbonate is negligible in $\mathrm{PM}_{10}$ at most European areas. Exceptions are coastal sites in south Europe (ten Brink et al., 2004; Sillanpää et al., 2005; Perrone et al., 2011) or peculiar situations (Querol et al., 2009; Cuccia et al., 2011).

Briefly, in the first part of the TOT analysis the sample is heated in an inert atmosphere (He) using different thermal ramps depending on the protocol in use. Then, the second part of the analysis is carried out in an oxidising atmosphere $\left(\mathrm{He} / \mathrm{O}_{2}\right.$ mixture, $\left.90 / 10 \%\right)$ (Birch and Cary, 1996). The carbon evolving during heating is completely oxidised to $\mathrm{CO}_{2}$ by a $\mathrm{MnO}_{2}$ catalyst and then reduced to $\mathrm{CH}_{4}$ to be quantified by a flame ionisation detector (FID).

To account for PyC formation, the transmission of a laser beam through the sample is constantly monitored during the analysis. Transmittance usually decreases throughout the He-step, indicating the formation of light-absorbing PyC. In the $\mathrm{He} / \mathrm{O}_{2}$ phase, an increase of the laser signal is registered and the PyC evolution is conventionally assumed completed when the transmittance reaches its initial value. Carbon evolving after this point (called split-point) is then considered as EC.

In this work, three thermal protocols mainly differing for the highest temperature in the $\mathrm{He}$ atmosphere were tested (see Table 1 for details). The protocol called He-870 is very similar to NIOSH2 (Maenhaut and Clayes, 2007) and ACEAsia base (Schauer et al., 2003). The He-580 is a low temperature and time variable protocol which is a proxy of the Desert Research Institute IMPROVE_A protocol (Chow et al., 2007) implemented on a thermal-optical transmittance instrument. The third protocol is EUSAAR_2 (Cavalli et al., 2010), which has been recently proposed as a standard for carbon analysis on samples collected at European regional background sites. It is noteworthy that few samples analysed in our work by EUSAAR_2 required the last step in oxidising atmosphere to be prolonged in order to obtain a complete carbon evolution, as previously reported by other authors (Kuhlbusch et al., 2009; Gilardoni et al., 2011).

The protocols differ for temperature and duration of the heating steps. It is important to point out that the plateau temperatures and step time-lengths in He-870 and EUSAAR_2 are fixed. As for He-580, the plateau temperatures are fixed but the step time-lengths are variable; indeed, this protocol allows the complete evolution of the carbon at each step (i.e. each plateau lasts till the FID signal approaches to zero).

Of the two quartz filters sampled in parallel, one was analysed as-is (in the following named untreated sample) and the other was water-washed to remove water soluble compounds, as explained in Sect. 2.3. We analysed 26 untreated and 26 parallel washed samples using the three protocols. For each sample, only a $1 \mathrm{~cm}^{2}$ punch was analysed for each protocol.

\subsection{Washing procedure}

To set up the filter washing procedure, $\mathrm{PM}_{10}$ samples were collected at the location previously described (Sect. 2.1) using a high-volume sampler (flow rate: $30 \mathrm{~m}^{3} \mathrm{~h}^{-1}$ ) on $150 \mathrm{~mm}$ 
Table 1. Thermal protocols tested in this work.

\begin{tabular}{llllll}
\hline & \multicolumn{2}{c}{ He-870 } & \multicolumn{2}{c}{ He-580 } & \multicolumn{2}{c}{ EUSAAR_2 } \\
Atmosphere & Temp. $\left({ }^{\circ} \mathrm{C}\right)$ & Duration $(\mathrm{s})$ & Temp. $\left({ }^{\circ} \mathrm{C}\right)$ & Temp. $\left({ }^{\circ} \mathrm{C}\right)$ & Duration(s) \\
\hline $\mathrm{He} 1$ & 310 & 60 & 140 & 200 & 120 \\
$\mathrm{He} 2$ & 475 & 60 & 280 & 300 & 150 \\
$\mathrm{He} 3$ & 615 & 60 & 480 & 450 & 180 \\
$\mathrm{He} 4$ & 870 & 105 & 580 & 650 & 180 \\
$\mathrm{He}$ & Cool down & 80 & - & Cool down & 30 \\
$\mathrm{He} / \mathrm{O}_{2} 1$ & 550 & 45 & 580 & 500 & 120 \\
$\mathrm{He} / \mathrm{O}_{2} 2$ & 625 & 45 & 740 & 550 & 120 \\
$\mathrm{He} / \mathrm{O}_{2} 3$ & 700 & 45 & 840 & 700 & 80 \\
$\mathrm{He} / \mathrm{O}_{2} 4$ & 775 & 45 & & 850 & 80 \\
$\mathrm{He} / \mathrm{O}_{2} 5$ & 850 & 45 & & & \\
$\mathrm{He} / \mathrm{O}_{2} 6$ & 870 & 120 & & & \\
\hline
\end{tabular}

a Proxy of the NIOSH2 protocol.

b Proxy of the IMPROVE_A protocol.

diameter quartz fibre filters (QAT-UP, Pall Corporation), which allowed multiple tests on the same material.

Water soluble compounds were removed washing portions of the high volume sampled filters using MilliQ (Millipore) water. Each portion of the filter was placed in a filtration assembly - similar to the one reported by Yttri et al. (2009) suitably designed for this application. The washed area was $37 \mathrm{~mm}$ diameter wide (i.e. smaller than the total deposit area) to avoid the possible loss of sampled particles from the filter edge.

Tests were carried out to determine the amount of water needed for a complete removal of water soluble compounds so that different punches of the same sampled filter were washed using increasing water quantities. Residual TC concentrations measured by TOT were used to check the washing efficiency with different water quantities. It was noticed that the residual TC on the filter decreased when the water used for the washing increased, until a minimum TC quantity $\left(\mathrm{TC}_{\mathrm{W}}\right)$ was reached. The water quantity $\left(V_{\mathrm{H}_{2} \mathrm{O}}\right)$ necessary to reach $\mathrm{TC}_{\mathrm{W}}$ was different for each filter and depended on the initial TC load. A linear relationship $\left(R^{2}=0.99\right)$ was found between the TC load of the sample (in the range 20$\left.100 \mu \mathrm{g} \mathrm{cm}^{-2}\right)$ and $V_{\mathrm{H}_{2} \mathrm{O}}$ :

$V_{\mathrm{H}_{2} \mathrm{O}}(\mathrm{ml})=\frac{\mathrm{TC}\left(\frac{\mu \mathrm{g}}{\mathrm{cm}^{2}}\right)}{7.5\left(\frac{\mu g}{\mathrm{ml}}\right)} \cdot$ washed area $\left(\mathrm{cm}^{2}\right)$.

This relation was used to estimate the water quantity to be used for the washing of the low volume samples collected for testing different protocols. It is noteworthy that the minimum water quantity used corresponded to the amount necessary for washing a $20 \mu \mathrm{g} \mathrm{cm}^{-2} \mathrm{TC}$ loaded sample. After washing, filters were placed in open but dust-protected sieve-trays and air dried at room temperature for $24 \mathrm{~h}$.

The uniformity of the washed filter was tested measuring the TC concentration on three different punches (area: $1 \mathrm{~cm}^{2}$ ) taken from the same filter and washed with $V_{\mathrm{H}_{2} \mathrm{O}}$. Differences among the three values were lower than $10 \%$.

\section{Results}

\subsection{TC measurements}

TC was measured on untreated and water washed samples using the three protocols. In Fig. 1 the comparison between TC measured by the protocols is shown. As expected, a good agreement was found among the different protocols; indeed, TC quantification is not dependent on the thermal treatment as previously found in different inter-comparison exercises (Schmid et al., 2001; Watson et al., 2005; and therein cited literature).

The TC results variability on each sample was evaluated as the ratio between the standard deviation of the three TC measurements and the average concentration value.

In the untreated samples, the variability was $4 \%$ on average (range of TC concentration: $17.6-57.0 \mu \mathrm{g} \mathrm{cm}^{-2}$ ). This estimate is consistent with the $\pm 5 \%$ measurement precision on TC values and $0.2 \mu \mathrm{g} \mathrm{cm}^{-2}$ as minimum uncertainty reported for this instrument (Subramanian et al., 2006). Nine field blanks were also analysed. The TC content in untreated field blanks was in the range $0.4-3.5 \mu \mathrm{g} \mathrm{cm}^{-2}$.

The average TC variability in the washed samples was $9 \%$. Four field blanks were also washed and their TC content was in the range $0.7-3.2 \mu \mathrm{g} \mathrm{cm}^{-2}$. These values are comparable to those measured on untreated field blanks; therefore, our washing procedure did not introduce any systematic filter contamination. Moreover, the comparison between the TC variability on untreated and washed samples indicates that our washing procedure did not significantly affect the filter uniformity (i.e. no more than $5 \%$ ). 

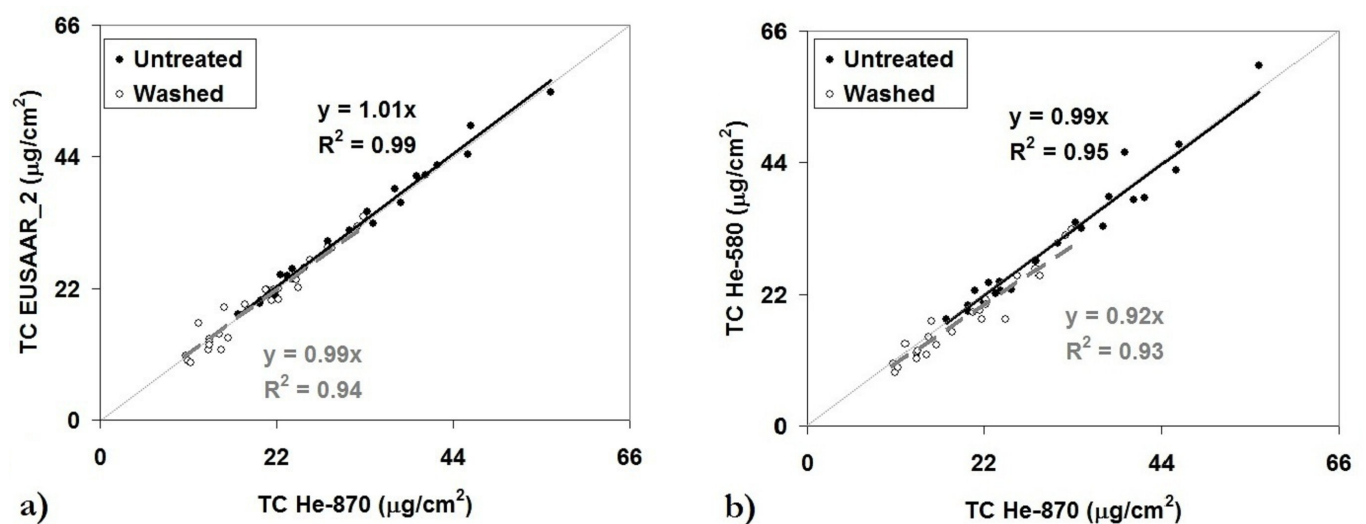

Fig. 1. Comparison between the TC results obtained by EUSAAR_2 and He-870 (a), and He-580 and He-870 (b) on untreated and washed filters.

\subsection{EC measurements}

EC results obtained by the three protocols were compared for both the untreated and washed samples. There was one outlier in the dataset with an EC concentration exceeding $15 \mu \mathrm{g} \mathrm{cm}^{-2}$. Previous works evidenced that the transmittance variation through heavily loaded filters (i.e. samples with $\mathrm{EC}>15 \mu \mathrm{g} \mathrm{cm}^{-2}$ ) cannot be correctly monitored because the initial laser signal is too low (Subramanian et al., 2006; Wallén et al., 2010), thus the outlier was excluded from the database. It is noteworthy that EC concentration was higher than $5.5 \mu \mathrm{g} \mathrm{cm}^{-2}$ in about half of the $9 \mathrm{~h}$ samples collected at our station. Therefore, if $24 \mathrm{~h}$ instead of $9 \mathrm{~h} \mathrm{sam}-$ plings had been carried out, EC concentration would have been higher than $15 \mu \mathrm{g} \mathrm{cm}^{-2}$ in one half of the samples, preventing the detection of transmittance variations during the He step. This observation is of particular interest because it evidences that traditional $24 \mathrm{~h}$ samplings in heavily polluted areas can limit the possibility to obtain reliable EC concentrations by the TOT method.

EC results obtained by the three protocols on both untreated and washed samples showed a good correlation $\left(R^{2}>\right.$ 0.87). Agreement in EC determination by the low temperature protocols was found (He-580 vs. EUSAAR_2 slope was 1.06 and 1.12 for untreated and washed samples, respectively). On the contrary, a disagreement up to a factor 1.6 for untreated samples was found when He-870 was compared to the lower temperature protocols (Fig. 2a, b). It is noteworthy that the disagreement between EUSAAR_2 and He870 reduces from 1.49 to $1.24(-17 \%)$ after filter washing. As for He-580, the reduction was lower (from 1.59 to 1.42 , $-11 \%$, after filter washing) probably because He-580 protocol allowed the complete carbon evolution at each temperature step, thus reducing pyrolysis even in untreated samples and limiting the advantages of washing the filters.

As expected, these results show that the removal of water soluble compounds from the filter is effective in reducing the differences among the EC values measured by different protocols. However, the removal of soluble compounds is not enough to obtain a full agreement among protocols as EC quantification depends also on other parameters, as it will be shown in the following sections.

Another finding was that EC concentrations were generally (in $83 \%, 67 \%$ and $79 \%$ of the cases for He-870, EUSAAR 2 and He-580, respectively) higher in the washed than in the untreated samples; the increases were up to $54 \%$ (with $\mathrm{He}-870$ ), $24 \%$ (with EUSAAR_2), and $43 \%$ (with $\mathrm{He}-580$ ) of the EC measured on untreated filters. This result suggests that measurements on untreated filters can lead to EC underestimation. One explanation might be that the untreated samples contain soluble compounds that catalyse the premature combustion of EC, which in turn yields lower EC values (see also Sect. 3.3).

The role of the carbon fraction evolving in He at high temperature (see Sect. 3.3) and PyC formation (see Sect. 3.5) were explored to better understand differences among protocols and between washed and untreated samples, in order to choose the most suitable thermal treatment for our samples.

\subsection{Matching the different protocols: the nature of carbon evolving at high temperature in the inert atmosphere}

As mentioned before, EC results were protocol-dependent in both untreated and washed samples. One of the main differences among the tested protocols is the highest temperature in the He step. Subramanian et al. (2006) identified the carbon evolving at high temperature (about $850^{\circ} \mathrm{C}$ ) in the $\mathrm{He}$ atmosphere as responsible for the disagreement observed in EC results.

In our tests, a good agreement was found comparing the sum of the EC and the carbon fraction evolving in the $\mathrm{He} 4$ step in the $\mathrm{He}-870$ protocol (in the following called C_He4 $4_{870}$ ) to the EC values obtained by EUSAAR_2 and 

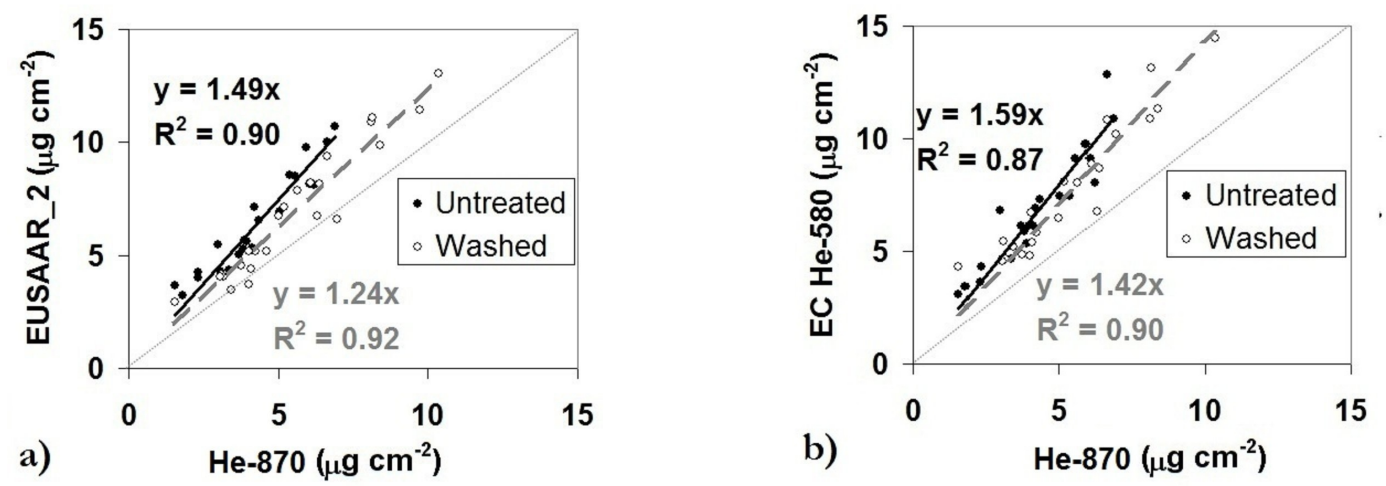

Fig. 2. Comparison between the EC results obtained by EUSAAR_2 and He-870 (a), He-580 and He-870 (b) on untreated and washed samples.

He-580 for both untreated and washed samples (Fig. 3). This result suggests that to obtain the most reliable EC estimate it is mandatory to understand the chemical nature of the C_He $4_{870}$ fraction (i.e. whether it is OC or EC) in the samples collected in the area of investigation. It is useful to point out that the concentration of this fraction in our samples is comparable to EC content, thus its wrong attribution can strongly affect EC determination.

Opposite to what reported in the literature (Chow et al., 2004; Subramanian et al., 2006), no significant increase in the laser signal was registered during the He4870 step (see Fig. 4), especially in the case of washed filters. The laser attenuation by the sample was calculated at the starting point of the analysis, at the maximum attenuation point, and at the end of the He step as $\mathrm{ATN}=-100 \ln \left(I_{j} / I_{0}\right)\left(I_{j}\right.$, with $j=1 . .3$ is the laser transmission measured at the three points of interest and $I_{0}$ is the laser signal at the end of the analysis, see Fig. 4a). The increase in the laser signal registered during the $\mathrm{He}_{870}$ step corresponded on average to a $4 \%$ (range $2 \%-7 \%$ ) variation of the initial attenuation on the washed samples and a $6 \%$ (range 3\%-12\%) on the untreated ones. The slight difference between washed and untreated samples is probably due to soluble compounds (e.g. sulphates or other salts) which can alter the thermal behaviour of the light-absorbing carbonaceous species and are removed by the washing procedure (Novakov and Corrigan, 1995; Yu et al., 2002; Hitzenberger and Rosati, 2010; Wang et al., 2010; and therein cited literature).

C_He4870 is not expected to be chemically homogeneous. However, the apparent average attenuation coefficient related to $\mathrm{C} \_\mathrm{He}_{870}$ (defined as the ratio between the ATN variation and the carbon evolved during the $\mathrm{He}_{870}$ step) was calculated to gain information on the optical properties of this fraction. The average attenuation coefficient was about $2.6 \mathrm{~m}^{2} \mathrm{~g}^{-1}$ and about $3 \mathrm{~m}^{2} \mathrm{~g}^{-1}$ for washed and untreated samples, respectively. These values are much lower than those reported in the literature for EC (about $20 \mathrm{~m}^{2} \mathrm{~g}^{-1}$ ) and

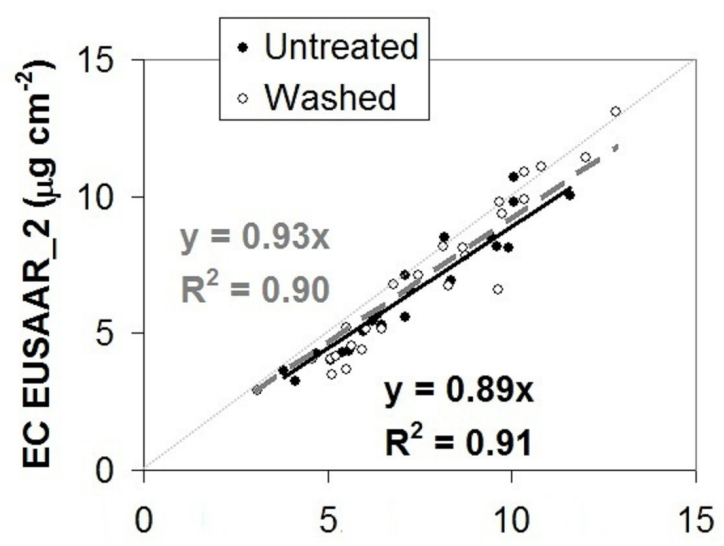

a) EC He-870 + C_He4 $870\left(\mu \mathrm{g} \mathrm{cm}^{-2}\right)$

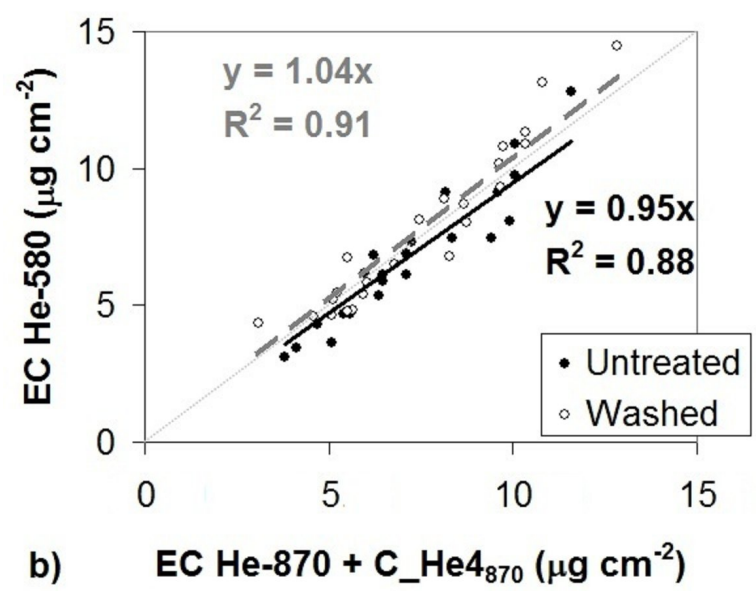

Fig. 3. EC measured by EUSAAR_2 (a) and He-580 (b)) vs. EC concentration obtained by the $\mathrm{He}-870$ protocol summed to the carbon fraction evolving in the $\mathrm{He}_{870}$ (i.e. EC He- $870+\mathrm{C}_{-} \mathrm{He}_{870}$ ). 
PyC (about $40-50 \mathrm{~m}^{2} \mathrm{~g}^{-1}$ ) on filters (Chow et al., 2004; Subramanian et al., 2006; Boparai et al., 2008) indicating that most of the $\mathrm{C} \_\mathrm{He}_{870}$ in our samples is not strongly lightabsorbing. Therefore, the $\mathrm{C}_{-} \mathrm{He}_{870}$ in this kind of samples is likely composed mainly by organic compounds showing a weak light attenuation and only a slight evolution of the light-absorbing material is registered (i.e. about $10 \%$ of the $\mathrm{C}_{-} \mathrm{He}_{870}$ is estimated to be light-absorbing). Moreover, a rough estimate of the EC evolved in $\mathrm{He}_{870}$ step was carried out assuming the EC attenuation coefficient as $20 \mathrm{~m}^{2} \mathrm{~g}^{-1}$. Comparing this value to the measured EC concentration - and considering that also $\mathrm{PyC}$ can contribute to light-absorbing carbon evolution during $\mathrm{He}_{870}$ - an upper limit for EC pre-combustion was calculated $(12 \%$ and $5 \%$ of the measured EC for untreated and washed samples, respectively).

With the aim of understanding the higher EC values measured by the lower temperature protocols compared to He870, EUSAAR_2 temperatures at the split point were analysed. As the split-point in EUSAAR_2 occurred in all cases at temperatures in the $560-710^{\circ} \mathrm{C}$ range, it is possible that the organic compounds evolving in $\mathrm{He}_{870}$ burnt together with the EC fraction when EUSAAR_2 was applied. Therefore, EC can be overestimated when our samples are analysed using the EUSAAR_2 protocol. However, it should be taken into account that this hypothesis needs further investigations because the thermal evolution occurs in different atmospheres $\left(\mathrm{He}\right.$ and $\left.\mathrm{He} / \mathrm{O}_{2}\right)$ and the organic compounds might behave differently. Similar results were found using He-580, where the split points were always detected during the oxygen step at $580^{\circ} \mathrm{C}$.

It is noteworthy that the $\mathrm{C} \_\mathrm{He} 4870$ value was lower $(-28 \%$ on average) on washed than on untreated samples. The presence of soluble compounds in the $\mathrm{C}_{-} \mathrm{He}_{870}$ is another indication of the existence of organic compounds evolving at high temperatures in $\mathrm{He}$; these organics can increase PyC and EC measured concentrations when using low temperature protocols.

The reduction of this organic fraction, which contributes to the protocols disagreement (Andreae and Gelencsér, 2006), can further explain the slight improvement in protocols comparability reported in Sect. 3.2.

\subsection{WSOC analysis}

For a better comprehension of the differences between the results obtained on untreated and washed samples, filter extracts were also analysed to determine the thermal behaviour of WSOC. To analyse water soluble compounds the water extracts obtained by all samples were mixed to obtain one single sample, vacuum-dried, and rinsed with methanol (Piazzalunga et al., 2010a). A drop of this solution was then deposited on $1 \mathrm{~cm}^{2}$ punches of a pre-fired quartz fibre filter. The punches were placed in open but dust-protected sieve-
Table 2. WSOC results obtained by different protocols in $\mu \mathrm{g} \mathrm{cm}^{-2}$.

\begin{tabular}{lcccccccc}
\hline Protocol & OC & EC & TC & He1 & He2 & He3 & He4 & PyC \\
\hline He-870 & 49.9 & 0.0 & 50.0 & 19.2 & 7.6 & 2.6 & 9.8 & 10.7 \\
He-580 & 45.0 & 1.1 & 46.1 & 7.5 & 9.2 & 9.4 & 2.0 & 17.0 \\
EUSAAR_2 & 47.6 & 1.0 & 48.6 & 11.7 & 6.9 & 6.8 & 4.2 & 17.9 \\
\hline
\end{tabular}

trays, air dried ( $2 \mathrm{~h}$ at room temperature), and analysed using the three protocols.

In Fig. 5 thermograms of WSOC obtained by He-870, EUSAAR_2, and He-580 protocols are shown.

As already found in previous works (Andreae and $\mathrm{Ge}-$ lencsér, 2006; Wallén et al., 2010), the $\mathrm{He} 1$ and $\mathrm{He} 4$ carbon fractions gave the highest signal when WSOC were analysed by He- 870 .

It is noteworthy that a substantially higher carbon quantity (about $+77 \%$ ) evolved in the $\mathrm{He} / \mathrm{O}_{2}$ phase with the lowtemperature protocols than with the $\mathrm{He}-870$ protocol, indicating that the He 4870 step was important to allow the WSOC evolution in the He phase.

The WSOC laser signal increased in the $\mathrm{He}_{870}$ step. The apparent attenuation coefficient for the $\mathrm{C}_{-} \mathrm{He}_{870}$ was about $5 \mathrm{~m}^{2} \mathrm{~g}^{-1}$, indicating again that most of this carbon fraction was weakly light-absorbing. Moreover, the few lightabsorbing carbon evolving in $\mathrm{He}_{870}$ was $\mathrm{PyC}$ in this case, as no EC was expected in WSOC due to the extraction procedure. This is a further confirmation that the EC precombustion estimates given in Sect. 3.3 have to be considered as upper limits.

Results on water extracts obtained by the three protocols (see Table 2) showed that no EC was measured during the analysis by the $\mathrm{He}-870$ protocol, while about $1 \mu \mathrm{gC} \mathrm{cm}-2$ was observed using the low-temperature protocols.

This observation further suggests that in the Milan urban atmosphere organic compounds exist, which evolve in the $\mathrm{He}$ step at a temperature in the $650-870{ }^{\circ} \mathrm{C}$ range (about $20 \%$ of WSOC) and are weakly light-absorbing. In this work, these compounds have been demonstrated to interfere with EC determination when low-temperature protocols are used for the analysis, leading to a possible EC overestimation.

Part of these compounds can be ascribed to HULIS (HUmic-Like Substances), which are weakly absorbing materials with a biogenic origin or generated during biomass burning (Andreae and Crutzen, 1997; Andreae and Gelencsér, 2006; Iinuma et al., 2007; Schmidl et al., 2008). HULIS are mainly oxidised at temperatures higher than $600^{\circ} \mathrm{C}$.

It should be noted that wood burning is a not-negligible emission source in the Milan urban area during wintertime. The contribution of its primary component was estimated in the range $6-17 \%$ of the $\mathrm{PM}_{10}$ mass in Milan during winter periods (Bernardoni et al., 2011; Piazzalunga et al., 2011). 

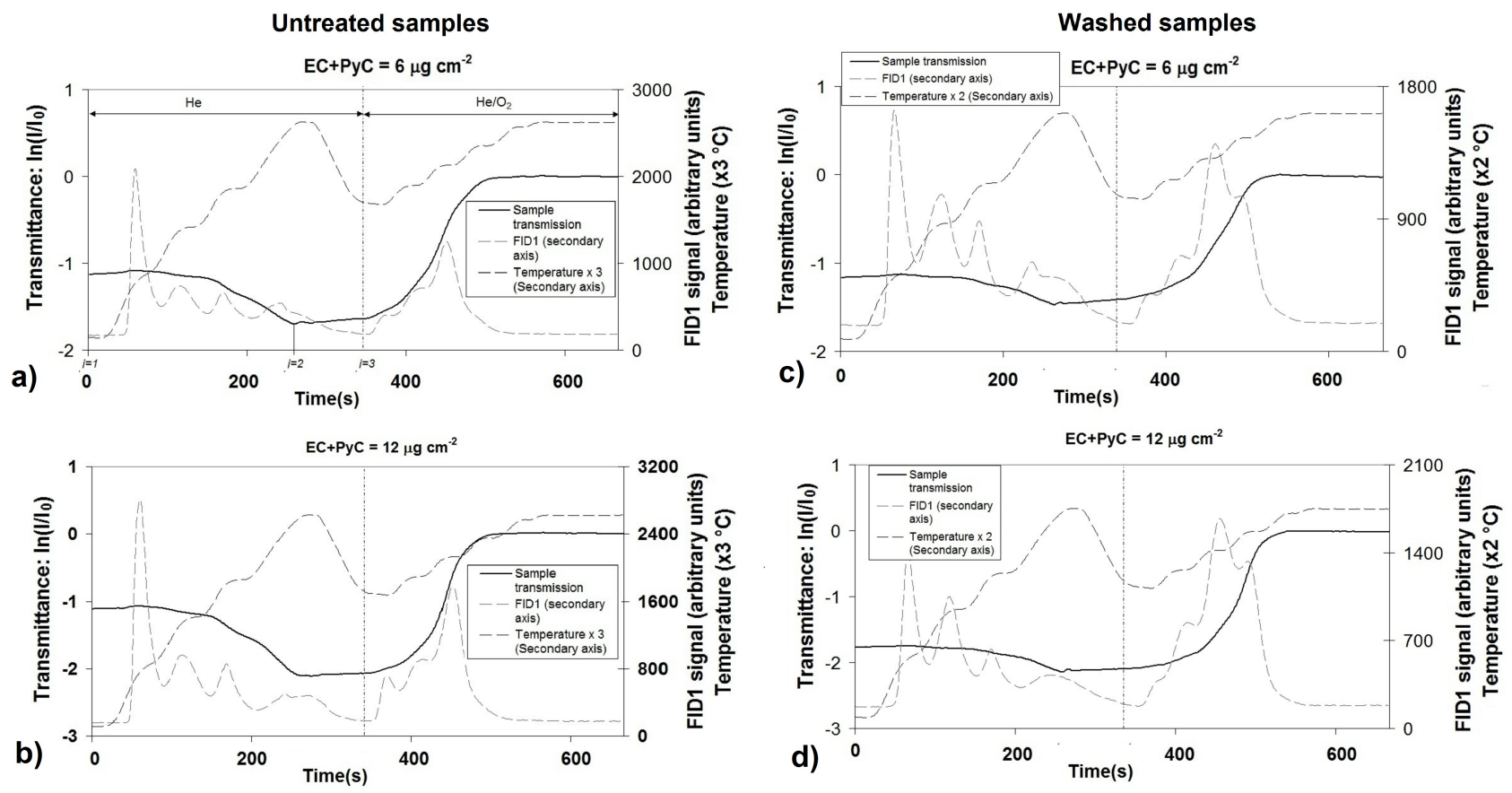

Fig. 4. Thermograms of untreated and washed sample for low (a and $\mathbf{c}$ ) and high (b and d) loaded samples. In Fig. 4a, the beginning of the analysis $(j=1)$, the point of minimum laser signal $(j=2)$ and the switching point $(j=3$ and dashed vertical line $)$ between the He and $\mathrm{He} / \mathrm{O}_{2}$ atmosphere are also reported.

Following Varga et al. (2001) preliminary HULIS measurements had been carried out by our group (Fermo et al., 2009); the results showed that HULIS can account for the 30-50\% of the $\mathrm{OC}$ in the Milan urban area during wintertime.

In the same samples analysed by the three protocols also levoglucosan - a marker for biomass burning (Simoneit and Elias, 2001) - was measured using the methodology reported in detail in Piazzalunga et al. (2010b). The presence of levoglucosan (concentration range: $0.6-4.0 \mu \mathrm{g} \mathrm{cm}^{-2}$ and levoglucosan carbon/TC $=3 \%$ on average) in our samples indicated a not negligible contribution due to wood burning during the investigated period, which can explain the presence of an important refractory, not strongly light-absorbing fraction.

It is noteworthy that the significant contributions due to biomass burning products makes low-temperature protocols not suitable for a correct assessment of the EC content in our samples because low-temperature TOT protocols can strongly overestimate it.

\subsection{Pyrolitic carbon formation}

It is well-known that PyC formation is another important source of troubles for OC/EC quantification. Indeed, literature studies (Yang and Yu, 2002) showed that neither of the following statements - necessary for a correct EC quantification - is respected in thermal-optical analysis: (a) pyrolytic carbon evolves before EC during the analysis; (b) pyrolytic carbon and OC have the same light absorption coefficient.

Therefore, if $\mathrm{PyC}$ formation is minimised, the analysis results are more reliable.

Figure 6 shows the comparison between the thermal evolution of one untreated and one washed sample with the EUSAAR_2 and the He-870 protocols. Strong reductions in the carbon evolving in the washed filter can be noticed both in the $\mathrm{He}$ and $\mathrm{He} / \mathrm{O}_{2}$ phase. A reduction of the carbon signal in the $\mathrm{He} / \mathrm{O}_{2}$ phase was found also for the He-580 protocol, but no thermogram superimposition is possible due to the variable time lengths in the analysis performed by this protocol.

The carbon evolving in the $\mathrm{He} / \mathrm{O}_{2}$ step was compared among the tested protocols to gain information on PyC formation. It was assumed that carbon evolving in oxygen with the EUSAAR_2 and He-580 protocols is comparable to that evolved in the He-870 but only with the addition of the C_He 4870 contribution (in the following all these quantities will be called $\mathrm{He} / \mathrm{O}_{2}$ carbon), according to the considerations reported in Sect. 3.3. $\mathrm{He} / \mathrm{O}_{2}$ carbon represents the sum of native EC, the refractory fraction of $\mathrm{OC}$, and $\mathrm{PyC}$ formed during the thermal treatment. The $\mathrm{He} / \mathrm{O}_{2}$ carbon concentrations are represented in Fig. 7 separately for untreated and washed samples. Since the native EC on the filter does not depend on the chosen protocol, differences in $\mathrm{He} / \mathrm{O}_{2}$ measurements among protocols can be ascribed only to differences in PyC formation in the first part of the analysis. 

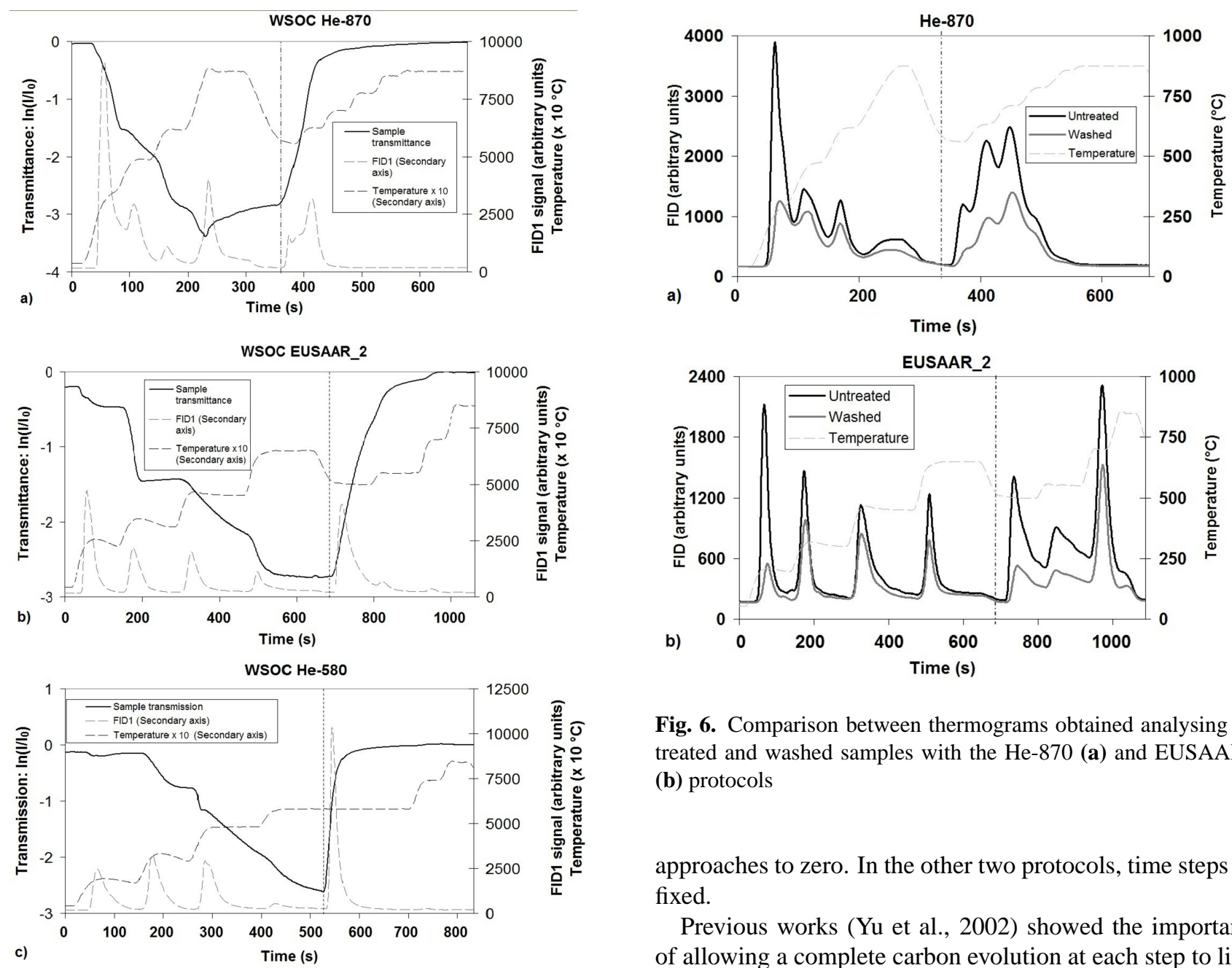

Fig. 6. Comparison between thermograms obtained analysing untreated and washed samples with the He-870 (a) and EUSAAR_2 (b) protocols

Fig. 5. WSOC thermograms obtained by He-870 (a), EUSAAR_2 (b), and He-580 (c). The vertical line indicates the switch between $\mathrm{He}$ and $\mathrm{He} / \mathrm{O}_{2}$ atmosphere.

Few differences were registered between He-870 and EUSAAR_2 $\mathrm{He} / \mathrm{O}_{2}$ carbon (on average $7 \%$ in the untreated samples and $12 \%$ in the washed samples), whereas the He580 data were much lower (on average about $-32 \%$ in both cases). Thus, the He-870 and EUSAAR_2 protocols seemed to produce comparable $\mathrm{PyC}$ quantities in samples collected in a polluted urban area; on the contrary, $\mathrm{PyC}$ formed by He580 was much lower. This finding was opposite to what reported by Cavalli et al. (2010) for the EUSAAR_2 protocol but they referred to samples collected at regional background stations in Europe and likely characterised by a very different chemical composition.

The observed differences on the $\mathrm{He} / \mathrm{O}_{2}$ carbon could be due to the time duration of the He steps in the different protocols. In the He-580 protocol the steps are variable; the duration of each temperature plateau is such to allow the evolution of carbon at a specific temperature step until the peak

approaches to zero. In the other two protocols, time steps are fixed.

Previous works (Yu et al., 2002) showed the importance of allowing a complete carbon evolution at each step to limit PyC formation. As for our samples, Fig. 8 shows that when the He step duration in EUSAAR_2 was comparable to the $\mathrm{He}-580$ one, differences in the $\mathrm{He} / \mathrm{O}_{2}$ carbon between these protocols approached to zero. On the contrary, the shorter was the step time in EUSAAR_2 compared to the He-580 one the higher was the $\mathrm{He} / \mathrm{O}_{2}$ carbon (i.e. $\mathrm{PyC}$ ) formed using EUSAAR_2.

Focusing on the differences between untreated and washed samples, reduction of the $\mathrm{He} / \mathrm{O}_{2}$ carbon was registered after washing ( $-40 \%$ for He- 870 and EUSAAR_ 2 and $-30 \%$ for He-580). Therefore, the missing fraction in the washed samples was either soluble or produced by the thermal treatment of soluble compounds. Thus, the washing procedure applied to our samples reduced possible interferences in the measurements (e.g. presence of refractory organic carbon and inorganic compounds which modify the thermal behaviour as well as PyC formation), improving the protocols agreement on EC measurements as shown in Sect. 3.2. The lower reduction in the He-580 protocol can be justified considering that this protocol is less prone to pyrolysis than the others even in our untreated urban samples, therefore limiting the possibility of reduction of the pyrolysing carbon component after soluble compounds removal. 

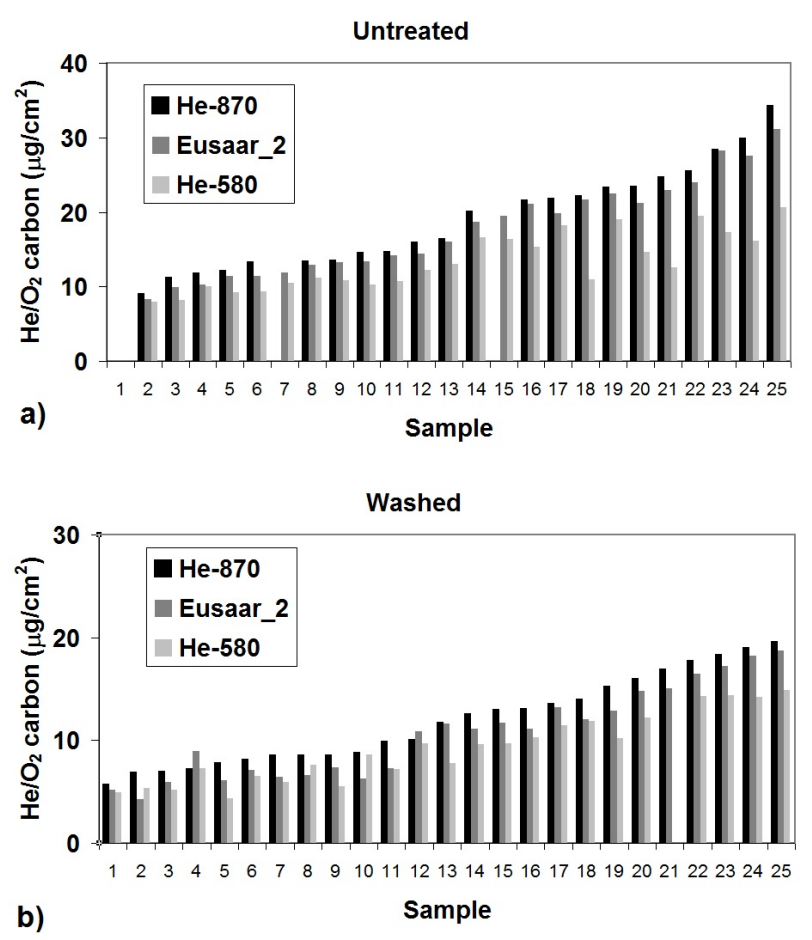

Fig. 7. $\mathrm{He} / \mathrm{O}_{2}$ carbon in untreated (a) and washed (b) samples

\section{Conclusions}

This work aimed at the evaluation of the best approach to analyse EC and OC by TOT in real aerosol samples collected in a polluted urban area. Tests were carried out on both washed and untreated samples collected during a winter period in Milan (Po valley, Italy). Results obtained by TOT analysis using three different thermal protocols were discussed.

As expected, EC values measured by the three tested protocols were different. The main difference was ascribed to the carbon fraction evolving during the step at $870^{\circ} \mathrm{C}$ in $\mathrm{He}$ atmosphere $\left(\mathrm{C}_{-} \mathrm{He}_{870}\right)$. It was demonstrated that C_He4 ${ }_{870}$ evolved in $\mathrm{He} / \mathrm{O}_{2}$ atmosphere with the two lowertemperature protocols. The evolution of this fraction before or after the split-point can differently affect the EC measured by the lower temperature protocols. It was proved that C_He $4_{870}$ was mainly not light-absorbing in our samples, thus it had to be considered mainly OC. It is noteworthy that the $\mathrm{C} \_\mathrm{He} 4_{870}$ quantity in our samples was comparable to the $\mathrm{EC}$ one, whereas the upper limit to EC pre-combustion using He- 870 was estimated to be $12 \%$ and $6 \%$ of the EC measured on untreated and washed samples, respectively. Therefore, the He- 870 protocol prevented EC overestimation when analysing samples collected in polluted urban environments like Milan.

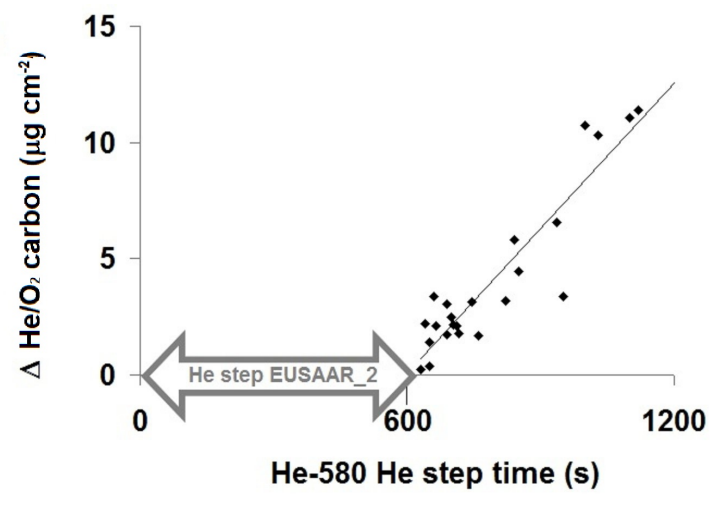

Fig. 8. Differences in $\mathrm{He} / \mathrm{O}_{2}$ carbon evolving applying EUSAAR_2 and $\mathrm{He}-580$ protocols ( $\triangle \mathrm{He} / \mathrm{O}_{2}$ carbon) as a function of the He step duration in the He-580 protocol.

WSOC were also analysed as they are significant contributors to PyC. The washing procedure used to remove WSOC from our samples resulted in a more reliable EC estimation as the PyC formation was limited. Moreover, - as WSOC contribute to part of the C_He 4870 - their removal allowed also a slight improvement in the protocols comparability.

In summary, our tests on real samples - characterised by a chemical composition typical of an area affected by a complex mixture of pollution sources - suggest that protocols reaching high temperatures in $\mathrm{He}$ atmosphere are preferable to low-temperature ones to get rid of typical interferences which affect EC results. Moreover, our results indicate that the best approach to analyse carbon in urban aerosol samples should consider steps long enough for complete carbon evolution in order to reduce pyrolysis formation.

Acknowledgements. The authors are grateful to Chiara Abate and Chiara Paganelli for their contribution to the experiment both in the laboratory and on the field.

Edited by: T. Kirchstetter

\section{References}

Andreae, M. O. and Crutzen, P. J.: Atmospheric Aerosols: Biogeochemical Sources and Role in Atmospheric Chemistry, Science, 276, 1052-1058, 1997.

Andreae, M. O. and Gelencsér, A.: Black carbon or brown carbon? The nature of light-absorbing carbonaceous aerosols, Atmos. Chem. Phys., 6, 3131-3148, doi:10.5194/acp-6-3131-2006, 2006.

Bernardoni, V., Vecchi, R., Valli, G., Piazzalunga, A., and Fermo, P.: $\mathrm{PM}_{10}$ source apportionment in Milan (Italy) using timeresolved data, Sci. Total Environ., 409, 4788-4795, 2011.

Birch, M. E. and Cary, R. A.: Elemental Carbon-Based Method for Monitoring Occupational Exposures to Particulate Diesel Exhaust, Aerosol Sci. Tech., 25, 221-241, 1996. 
Boparai, P., Lee, J., and Bond, T. C.: Revisiting Thermal-Optical Analyses of Carbonaceous Aerosol Using a Physical Model, Aerosol Sci. Tech., 42, 930-948, 2008.

Cavalli, F., Viana, M., Yttri, K. E., Genberg, J., and Putaud, J.P.: Toward a standardised thermal-optical protocol for measuring atmospheric organic and elemental carbon: the EUSAAR protocol, Atmos. Meas. Tech., 3, 79-89, doi:10.5194/amt-3-79-2010, 2010.

Chow, J. C., Watson, J. G., Pritchett, L. C., Pierson, W. R., Frazier, C. A., and Purcell, R. G.: The DRI Thermal/Optical Reflectance Carbon Analysis System: Description, Evaluation, and Applications in US Air Quality Studies, Atmos. Environ. A-Gen., 27, 1185-1201, 1993.

Chow, J. C., Watson, J. G., Crow, D., Lowental, D. H., and Merrifield, T.: Comparison of IMPROVE and NIOSH Carbon Measurements, Aerosol Sci. Technol., 34, 23-34, 2001.

Chow, J. C., Watson, J. G., Chen, L.-W. A., Arnott, W. P., and Moosmüller, H.: Equivalence of Elemental Carbon by Thermal/Optical Reflectance and Transmittance with Different Temperature Protocols, Environ. Sci. Technol., 38, 4414-4122, 2004.

Chow, J. C., Watson, J. G., Chen, L. W., Chang, M. C., Robinson, N. F., Trimble, D., and Kohl, S.: The IMPROVE_A temperature protocol for thermal/optical carbon analysis: maintaining consistency with a long-term database, J. Air Waste Manage, 57, 1014-1023, 2007.

Conny, J. M., Klinedinst, D. B., Wight, S. A., and Paulsen, J. L.: Optimizing Thermal-Optical Methods for Measuring Atmospheric Elemental (Black) Carbon: A Response Surface Study, Aerosol Sci. Technol., 37, 703-723, 2003.

Cuccia, E., Piazzalunga, A., Bernardoni, V., Brambilla, L., Fermo, P., Massabò, D., Molteni, U., Prati, P., Valli, G., Vecchi, R.: Carbonate measurements in $\mathrm{PM}_{10}$ near the marble quarries of Carrara (Italy) by infrared spectroscopy (FT-IR) and source apportionment by positive matrix factorization (PMF), Atmos. Environ., 45, 6481-6487, 2011.

Fermo, P., Piazzalunga, A., Tuccillo, F., Brambilla, L., Cazzuli, O., Vecchi, R., and Valli, G.: Analytical methods for quantification and characterization of HULIS (HUmic Like Substances) in atmospheric aerosol, European Aerosol Conference, Karlsruhe, Germany, 6-11 September 2009, T022A18, 2009.

Gilardoni, S., Vignati, E., Marmer, E., Cavalli, F., Belis, C., Gianelle, V., Loureiro, A., and Artaxo, P.: Sources of carbonaceous aerosol in the Amazon basin, Atmos. Chem. Phys., 11, 27472764, doi:10.5194/acp-11-2747-2011, 2011.

Hitzenberger, R. and Rosati, B.: Laboratory investigation of interferences in thermal and optical carbon analysis, International Aerosol Conference, Helsinki, Finland, 29 August-3 September 2010, 3A3, 2010.

Iinuma, Y., Brüggemann, E., Gnauk, T., Andreae, M. O., Helas, G., Müller, K., Parmar, R., and Herrmann, H.: Source characterization of biomass burning particles: The combustion of selected European conifers, African hardwood, savannah grass, German peat and Indonesian peat, J. Geophys. Res., 112, D08209, doi:10.1029/2006JD007120, 2007.

Kuhlbusch, T. A. J., Borowiak, A., Gelenscer, A., Genberg, J., Gladtke, D., Maenhaut, W., Pio, C., Popoviecheva, O., Putaud, J.-P., Quincy, P., Sciare, J., ten Brink, H., Viana, M., and Yttri, K.E.: Measurement of Elemental and Organic carbon in Europe, JRC Scientific and Technical Reports (EUR collection),
EUR23992 EN, available at http://publications.jrc.ec.europa.eu/ repository/handle/111111111/7803/, 2009.

Maenhaut, W. and Clayes, M.: Characterisation and sources of carbonaceous atmospheric aerosol, in: Scientific support plan for a sustainable development policy (SPSD II), Belgian Science Policy, Bruxelles, Belgium, 2007.

Novakov, T. and Corrigan, C. E.: Thermal Characterization of Biomass Smoke Particles, Mikrochim. Acta, 119, 157-166, 1995.

Perrone, M. R., Piazzalunga, A., Prato, M., and Carofalo, I.: Composition of Fine and Coarse Particles in a coastal site of the Central Mediterranean: carbonaceous specie contributions, Atmos. Environ., doi:10.1016/j.atmosenv.2011.04.030, in press, 2011.

Piazzalunga, A., Abate, C., Bernardoni, V., Bianchi, F., Fermo, P., Paganelli, C., Valli, G., and Vecchi, R.: BC/EC assessment on real samples by optical/thermal methods with and without WSOC removal and using different protocols, International Aerosol Conference, Helsinki, Finland, 29 August-3 September 2010, 11D4, 2010a.

Piazzalunga, A., Fermo, P., Bernardoni, V., Vecchi, R., Valli, G., and De Gregorio, M. A.: A simplified method for levoglucosan quantification in wintertime atmospheric particulate matter by high performance anion-exchange chromatography coupled with pulsed amperometric detection, Int. J. Environ. An. Ch., 90, 934947, 2010b.

Piazzalunga, A., Belis, C., Bernardoni, V., Cazzuli, O., Fermo, P., Valli, G., Vecchi, R.: Estimates of wood burning contribution to PM by the macro-tracer method using tailored emission factors, Atmos. Environ., doi:10.1016/j.atmosenv.2011.09.008, in press, 2011.

Querol, X., Pey, J., Pandolfi, M., Alastuey, A., Cusack, M., Pérez, N., Moreno, T., Viana, M., Mihalopoulos, N., Kallos, G., and Kleanthous, S.: African dust contributions to mean ambient $\mathrm{PM}_{10}$ mass-levels across the Mediterranean Basin, Atmos. Environ., 43, 4266-4277, 2009.

Schauer, J. J., Mader, B. T., Deminter, J. T., Heidmann, G., Bae, M. S., Seinfeld, J. H., Flagan, R. C., Cary, R. A., Smith, D., Huebert, B. J., Bertram, T., Howell, S., Kline, J. T., Quinn, P., Bates, T., Turpin, B., Lim, H. J., Yu, J. Z., Yang, H., and Keywood, M. D.: ACE-Asia Intercomparison of a Thermal-Optical Method for the Determination of Particle-Phase Organic and Elemental Carbon, Environ. Sci. Technol., 37, 993-1001, 2003.

Schmid, H., Laskus, L., Abraham, H. J., Baltensperger, U., Lavanchy, V., Bizjak, M., Burba, P., Cachier, H., Crow, D., Chow, J., Gnauk, T., Even, A., ten Brink, H. M., Giesen, K.-P., Hitzenberger, R., Hueglin, C., Maenhaut, W., Pio, C., Carvalho, A., Putaud, J.-P., Toom-Sauntry, D., and Puxbaum H.: Results of the "carbon conference" international aerosol carbon round robin test stage I, Atmos. Environ., 35, 2111-2121, 2001.

Schmidl, C., Bauer, H., Dattler, A., Hitzenberger, R., Weissenboeck, G., Marr, I. L., and Puxbaum, H.: Chemical characterisation of particle emissions from burning leaves, Atmos. Environ., 42, 9070-9079, 2008.

Simoneit, B. R. T. and Elias, V. O.: Detecting organic tracers from biomass burning in the atmosphere, Mar. Pollut. Bull., 42, 805810, 2001.

Sillanpää, M., Frey, A., Hillamo, R., Pennanen, A. S., and Salonen, R. O.: Organic, elemental and inorganic carbon in particulate matter of six urban environments in Europe, Atmos. Chem. 
Phys., 5, 2869-2879, doi:10.5194/acp-5-2869-2005, 2005.

Subramanian, R., Khlystov, A. Y., and Robinson, A. L.: Effect of Peak Inert-Mode Temperature on Elemental Carbon Measured Using Thermal-Optical Analysis, Aerosol Sci. Technol., 40, 763-780, 2006.

ten Brink, H., Maenhaut, W., Hitzenberger, R., Gnauk, T., Spindler, G., Even, A., Chi, H., Bauer, H., Puxbaum, H., Putaud, J.-P., Tursic, T., and Berner, A.: INTERCOMP2000: the comparability of methods in use in Europe for measuring the carbon content of aerosol, Atmos. Environ., 38, 6507-6519, 2004.

Varga, B., Kiss, G., Ganszky, I., Gelencsér, A., and Krivàcsy, Z.: Isolation of water-soluble organic matter in atmospheric aerosol, Talanta, 55, 561-572, 2001.

Vecchi, R., Valli, G., Fermo, P., D’Alessandro, A., Piazzalunga, A., and Bernardoni, V.: Organic and inorganic sampling artefacts assessment, Atmos. Environ., 43, 1713-1720, 2009.

Wallén, A., Lidén, G., and Hansson, H.-C.: Measured Elemental Carbon by Thermo-Optical Transmittance Analysis in WaterSoluble Extracts from Diesel Exhaust, Woodsmoke, and Ambient Particulate Samples, J. Occup. Environ. Hyg., 7, 35-45, 2010.
Wang, Y., Chung, A., and Paulson, S. E.: The effect of metal salts on quantification of elemental and organic carbon in diesel exhaust particles using thermal-optical evolved gas analysis, Atmos. Chem. Phys., 10, 11447-11457, doi:10.5194/acp-1011447-2010, 2010.

Watson, J. G., Chow, J. C., and Chen, L.-W. A.: Summary of Organic and Elemental carbon/Black Carbon Analysis Methods and Intercomparisons, Aerosol Air Qual. Res., 5, 65-102, 2005.

Yang, H. and Yu, J. Z.: Uncertainties in Charring Correction in the Analysis of Elemental and Organic Carbon in Atmospheric Particles by Thermal/Optical Methods, Environ. Sci. Technol., 36, 5199-5204, 2002.

Yttri, K. E., Dye, C., Braathen, O.-A., Simpson, D., and Steinnes, E.: Carbonaceous aerosols in Norwegian urban areas, Atmos. Chem. Phys., 9, 2007-2020, doi:10.5194/acp-9-2007-2009, 2009.

Yu, J. Z., Xu, J. H., and Yang, H.: Charring Characteristics of Atmospheric Organic Particulate Matter in Thermal Analysis, Environ. Sci. Technol., 36, 754-761, 2002.

Zhi, G., Chen, Y., Sheng, G., and Fu, J.: Effects of temperature parameters on thermal-optical analysis of organic and elemental carbon in aerosol, Environ. Monit. Assess., 154, 253-261, 2009. 